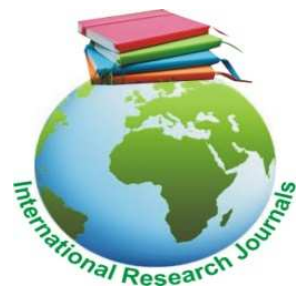

Journal of Medicine and Medical Sciences Vol. 9(1) pp. 009-014, January 2018

Available online http://www.interesjournals.org/JMMS

DOI: http:/dx.doi.org/10.14303/jmms.2016.139

Copyright (C) 2018 International Research Journals

Full Length Research Paper

\title{
Histological observation of the effect of aqueous extract of sorghum bicolor leaf sheath on paracetamol- induced liver damage in rats
}

\author{
Agbaje M. $\mathrm{A}^{1,2^{\star}}$, Nwoha P.U ${ }^{1}$, Adekomi D. $\mathrm{A}^{1}$, Olayode AA ${ }^{1}$, Bamisi O. ${ }^{3}$ \\ ${ }^{1}$ Department of Anatomy and Cell biology, Obafemi Awolowo University, lle-Ife, Osun State, Nigeria \\ ${ }^{2}$ Department of Anatomy, Ekiti State University, Ado Ekiti, Ekiti State, Nigeria \\ ${ }^{3}$ Department of Anatomy, University of Lagos, Akoka, Lagos State, Nigeria \\ Corresponding Author Email:agbajeadedoyin@gmail.com, phone: 07032398512
}

\begin{abstract}
Introduction: Acetaminophen is a severe hepatotoxic drug. This study was undertaken to examine the protective and ameliorative effects of aqueous extract of Sorghum Bicolor stem bark on acetaminophen induced hepatotoxicity in male albino rats. Materials and Methods: Thirty five adult wistar rats weighing 150 to $200 \mathrm{~g}$ were randomized into seven groups of five animals each. Group A (control) received $200 \mathrm{mg} / \mathrm{kg}$ body weight (bw) of distilled water for 7 days, Group B received $200 \mathrm{mg} / \mathrm{kg}$ body weight aqueous extract of Sorghum bicolor stem bark for 7 days, Group C received $300 \mathrm{mg} / \mathrm{kg}$ bw paracetamol for 1 day, Group D received $300 \mathrm{mg} / \mathrm{kg}$ bw paracetamol for 1 day plus aqueous extract of Sorghum bicolor stem bark $(200 \mathrm{mg} / \mathrm{kg} \mathrm{bw})$ for 7 days, Group E received $300 \mathrm{mg} / \mathrm{kg}$ bw paracetamol for 1 day plus silymarin $(100 \mathrm{mg} / \mathrm{kg} \mathrm{bw})$ for 7 days, Group F received $200 \mathrm{mg} / \mathrm{kg}$ bw aqueous extract of Sorghum bicolor stem bark for 7 days plus paracetamol $(300 \mathrm{mg} / \mathrm{kg}$ bw) for 1 day and Group G received silymarin $(100 \mathrm{mg} / \mathrm{kg} \mathrm{bw})$ and paracetamol $(300 \mathrm{mg} / \mathrm{kg} \mathrm{bw})$. All solutions were administered orally. At the end of the administration, animals were sacrificed under chloroform anesthesia, blood samples collected via cardiac puncture. Paraffin sections of liver were stained for histology using Hematoxylin and Eosin, and for histochemistry using Masson's trichome, Gordon \& Sweets, and Periodic Acid Schiff's staining techniques. Results: Results from this study showed that there was congestion of hepatic portal triad, dilated sinusoids, and there was necrosis of hepatocytes nuclei in group $\mathrm{C}$, compare with group $\mathrm{A}$ and group B, which showed normal liver architecture and hepatocytes, group D and G showed mild portal triad congestion, mild dilated sinusoids, presence of inflammatory cells, hepatocytes showed dysplastic changes, Group $\mathrm{E}$ an $\mathrm{F}$ showed mild portal triad congestion, mild dilated sinusoids, reduced inflammatory cells, and dysplastic changes of the hepatocytes. Conclusion: The results of this study indicated that $300 \mathrm{mg} / \mathrm{kg}$ bw of paracetamol was hepatotoxic, and Sorghum bicolor stem bark extract had ameliorative and protective effect on the Paracetamol-induced liver damage.
\end{abstract}

Keywords: Sorghum bicolor, Acetaminophen, Hepatotoxicity.

\section{INTRODUCTION}

Exposure to drugs and chemicals often induce toxicity to living organisms. Factors determining the toxicity include the pharmacokinetics of the compound, the metabolic fate of the compound and the target organ ability to respond to the toxic insult. During the last decades considerable attention has been focused on the involvement of oxygen free radical (OFR) in various diseases. Active oxygen molecules such as superoxide and hydroxyl radicals have been demonstrated to play important role in the inflammation process produced by ethanol, carbon tetrachloride or paracetamol (Rippka et. al. 1979). Despite the presence of strong antioxidant defense mechanism to counteract the OFR and to minimize the plausible oxidative damage, OFR dependent damage to DNA and other biomolecules accumulate during the life time of organism. Liver is the 
most important organ concerned with the biochemical activities in the human body,

It has great capacity to detoxicate toxic substances and synthesize useful principles. Therefore, damage to the liver inflicted by hepatotoxic agents is of grave consequences. (Subramoniam and Pushpangadan, 1999). There is an ever increasing need of an agent which could protect it from such damage.

Acetaminophen (Paracetamol, $\quad N$-acetyl- $p$ aminophenol; APAP) is also known as paracetamol, is widely used as prescription and over the counter analgesic and antipyretic agent (Trumper et. al. 2004). It is a safe drug when given in therapeutic doses but its overdose is fairly common since it has narrow therapeutic index. Acute overdoses of paracetamol can cause potentially fatal liver damage and, in rare individuals, a normal dose can do the same; Paracetamol toxicity is the foremost cause of acute liver failure. (Walker et. al.,1981). In view of severe undesirable side effects of synthetic agents, there is growing focus to follow systematic research methodology and to evaluate scientific basis for the natural compounds which are claimed to possess hepatoprotective activity, Sorghum bicolor is an indigenous African cereal and traditional plant that belongs to the grass family, the Gramineae. It is a plant that has been used as an anti-toxicant, antiabortive, cyanogenetic, demulcent (providing relief for cough), diuretics (drugs that help in discharge of urine) and emollient (skin soften and smoothen substance). The parts that are commonly used for herbal remedies include leaves, whole plant or grains. The root is used for the treatment of malaria in southern Rhodesia; the seeds for the treatment of breast diseases and diarrhoea; the stem for tubercular swellings.

In India, the plant is considered antihelminthic and insecticidal (Duke and Wain, 1981). Recently focus has been on the leaf sheath of sorghum bicolor being used as herbal remedy for anaemia and having a boosting effect on blood concentration hematinic potentials (Ogwumike, 2002). Aqueous extracts of Sorghum bicolor leaf sheaths has been shown to contain phenolic compounds and to possess hemopoietic and antioxidant properties in the rat (Akande et al. 2010). The presence of antioxidants in sorghum is believed to have reduced the risk of cancer, diabetes, heart disease, nerve disorders among others. Its health potentials, experts say reside in its rich nutrients essential for healthy living (Sofowora, 2008). This study investigated the ameliorative and protective potential of Sorghum bicolor stem bark on PCM-induced liver damage in wistar rats.

\section{MATERIALS AND METHODS}

\section{Drugs and chemicals}

Silymarin (Micro Labs Limited, (92, Sipcot Hosur - 635
126, India) Batch number SYFH0005) is marketed as a hepatotonic and it basically contains phospholipids with vitamins. Paracetamol powder was purchased from (M and B pharmaceutical Nigeria Plc.). All chemicals used were of analytic grade. Assay kits for Biochemical parameters carried out were purchased from Randox Laboratories Limited, UK.

\section{Drug preparations}

\section{Paracetamol}

Each capsule contains $500 \mathrm{mg}$ of Paracetamol. One capsule was dissolved in $1 \mathrm{ml}$ of distilled water. Then the equivalent of $300 \mathrm{mg} / \mathrm{kg}$ of the drug in the solution will be administered to the animal

\section{Silymarin}

Silymarin (100mg) will be weighed also using sensitive weighing balance and dissolved in $5 \mathrm{~mL}$ of water and stirred thoroughly (Jibrin. et al., 2012)

\section{Extraction of sorghum bicolor}

Dry stem bark leave sheath was obtained from herb sellers at Ile Ife, Osun State, Nigeria. The plant specimen was identified and authenticated by a Taxonomist at the Department of Botany, Obafemi Awolowo University, IleIfe and a voucher number was given. The leave sheath was air dried at room temperature for weeks, weighed every three days to ascertain the dryness of the leaves. The air dried leave sheath weighing $750 \mathrm{~g}$ was grounded into fine powder in an electric blender and the powdered. The powder weighing $500 \mathrm{~g}$ was extracted in aqueous solution $(50 \%)$ by percolation for $24 \mathrm{hrs}$. The mixture was filtered and the filtrate was allowed to evaporate at $40^{\circ} \mathrm{C}$ using a vacuum Rotary evaporator. The wet residue was freeze- dried using a vacuum freeze drier and stored in a desiccator. An aliquot portion of the crude extract residue was dissolved in distilled water for use on each day of the experiment.

\section{Animal care and management}

Thirty- five adult Male wistar rats weighing 150g - $200 \mathrm{~g}$ that were used in this study were obtained from the Animal House of the College of Health Sciences, Obafemi Awolowo University, Ile-Ife. The male rats were housed in separate cages. The animals were kept under normal environmental conditions with a 12 hrs light/dark cycle and had free access to standard rat pellet diet (Ladokun Feed mill PLC Ibadan, Nigeria) and water ad 
Table 1: Dose Regimen

\begin{tabular}{|l|}
\hline \multicolumn{1}{|c|}{ Experimental design } \\
\hline Animal groups Treatments \\
\hline Group I (Control) distilled water \\
Group II $200 \mathrm{mg} / \mathrm{Kg}$ b.w. AESBLS \\
Group III 300 $\mathrm{mg} / \mathrm{Kg}$ b.w. PCM \\
Group IV $300 \mathrm{mg} / \mathrm{Kg}$ b.w. PCM $+200 \mathrm{mg} / \mathrm{Kg}$ b.w. AESBLS \\
Group V 300mg/ Kg b.w. PCM $+100 \mathrm{mg} / \mathrm{Kg}$ b.w. SILYMARIN \\
Group VI 200mg/ Kg b.w. AESBLS $+300 \mathrm{mg} / \mathrm{Kg}$ b.w. PCM \\
Group VII 100mg/ Kg b.w. SILYMARIN $+300 \mathrm{mg} / \mathrm{Kg}$ b.w. PCM \\
b.w. (body weight), AESBLS (Aqueous extract of Sorghum bicolor leaf sheath), \\
PCM(paracetamol) \\
\hline
\end{tabular}

libitum. They were allowed to acclimatize in the laboratory for 2 weeks before the commencement of the study. The experimental procedures adopted in this study were in strict compliance with Experimental Animal Care and Use of Laboratory Animals in Biomedical Research, College of Health Sciences, Obafemi Awolowo University, Ile-Ife.

\section{Histopathological studies}

The method of Baker and Silverton was employed for the processing of liver for histopathological studies. (Baker and Silverton 1985)

\section{Photomicrograph}

The sections were examined under a LEICA research microscope (LEICA DM750, Switzerland) interfaced with digital camera (LEICA ICC50). Digital photomicrographs of stained sections of the kidney was taken at various magnifications.

\section{RESULTS AND DISCUSSION}

The use of plants for remedies has long been in existence and is among the most attractive sources for developing drugs. Any part of plant can be considered as herbs including leaves, leaf sheath and bark. Research has shown that these practices have produced results of proven efficacies comparable to conventional modern medicine (Nwogu, 2008). This study investigated the effect of sorghum bicolor on histoarchitecture of the liver in rats with PCM-induced liver damage.

Histological and histochemical results of this study clearly support earlier reports that PCM has hepatotoxic effect on the liver cells when taken at high doses (Ita et al., 2009), table 1 show Dose Regimen. In group C (paracetamol only) as shown in figures $1 \mathrm{C}$, and $2 \mathrm{C}$ shows Portal triad congestion, hepatic sinuses are dilated, the endothelia cells lining the vascular channels shows dysplastic changes and their was necrotic hepatocytes, also the presence of mild fibrosis (demonstration of young collagen fibres). Stroma with young collagen fibre in paracetamol alone treated group when compared with the control group. The photomicrograph of the group A (Normal control) and group B (Extract control) show normal histology of the liver with the hepatocytes, portal triad, the endothelia cell linings, the vascular channels showed no dysplastic changes, and hepatic sinuses showing normal liver histoarchitecture. This is an indication that aqueous extract of Sorghum bicolor does not have any adverse effects on liver structure and function and this is in conformity with Akande et al, (2009); Olayinka et al (2010) who reported that Sorghum bicolor has no toxic effects or undesired properties on the liver. Improvement in the histological lesions, which was characterized by mild central venous congestion and few necrotic hepatocytes with many normal and surviving hepatocytes and few necrotic hepatocytes indicating mild hepatic necrosis when compared to group $\mathrm{C}$ rat livers was evident in the groups treated with Sorghum bicolor extract and silymarin after paracetamol and before induced hepatoxicity significantly attenuated the effect of paracetamol on the liver cells and the histological architecture of the liver as shown in figures $1 \mathrm{D}, 2 \mathrm{D}, 1 \mathrm{E}$ and $2 \mathrm{E}$. A similar finding was reported by Olayinka et al. 2010 that Sorghum bicolor was able to ameliorate hepatotoxicity.

Pre-treatment with SB extract and silymarin before paracetamol administration significantly prevented the damage caused by the effect of paracetamol on the liver cells and the histological architecture of the liver as shown in figure $1 F, 2 F, 1 G$ and $2 G$ based on the histological observations.

\section{Masson trichrome}

Masson's trichrome staining techniques were used to demonstrate collagen fibre in this study. In the result, Collagen fibers stained green with Masson's trichrome 
012 J. Med. Med. Sci.

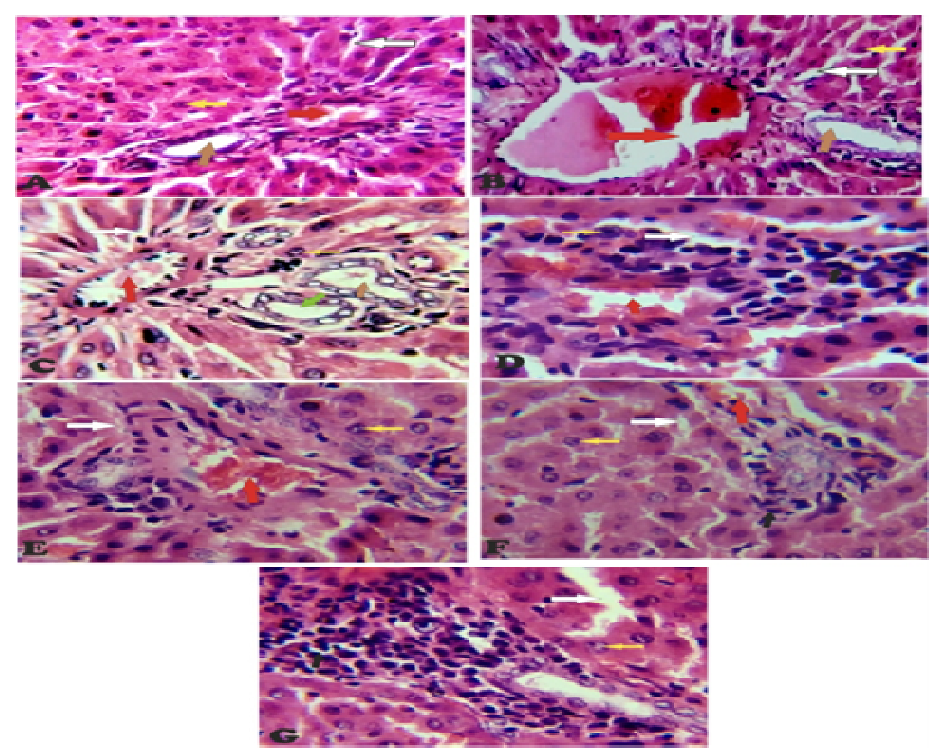

Figure 1: Representative Photomicrographs of the liver of control (A) and treated, (B, C, D, E, F, G) groups. Arrow represents (hepatocytes - yellow),(sinusoids - white), (central vein - blue), (inflammatory cells black), (bile ducts - green), (portal vein - red), (hepatic artery - brown) ( $\mathrm{H}$ and $\mathrm{E} X 400)$.

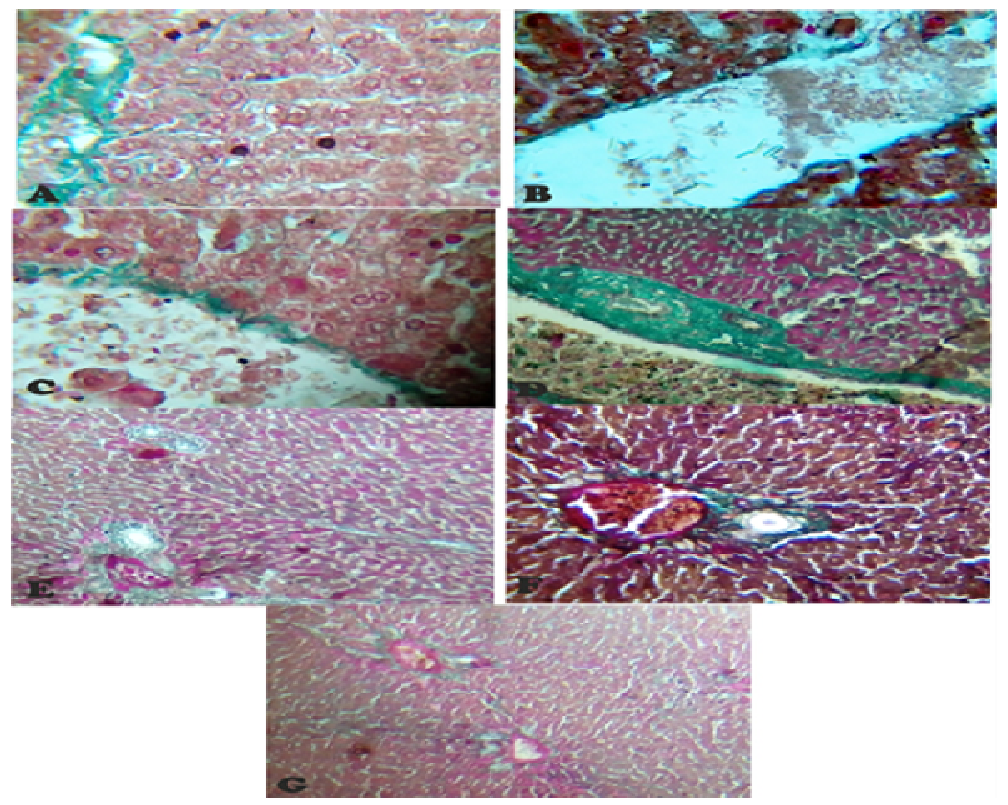

Figure 2: Representative Photomicrographs of the liver of control $(A)$ and treated, $(B, C, D, E, F, G)$ groups. Observe the presence of mild fibrosis following PCM alone treatment as shown in figure 4C (MT X 400)

stain, and the nuclei stained black. The collagen fibre in the A normal control group, B (sorghum bicolor only), D
$(\mathrm{PCM}+\mathrm{SB}), \mathrm{E}(\mathrm{PCM}+\mathrm{SILY}), \mathrm{F}(\mathrm{SB}+\mathrm{PCM})$, and $\mathrm{G}$ (SILY+PCM) all appear normal with no fibrosis and 
Agbaje et al. 013

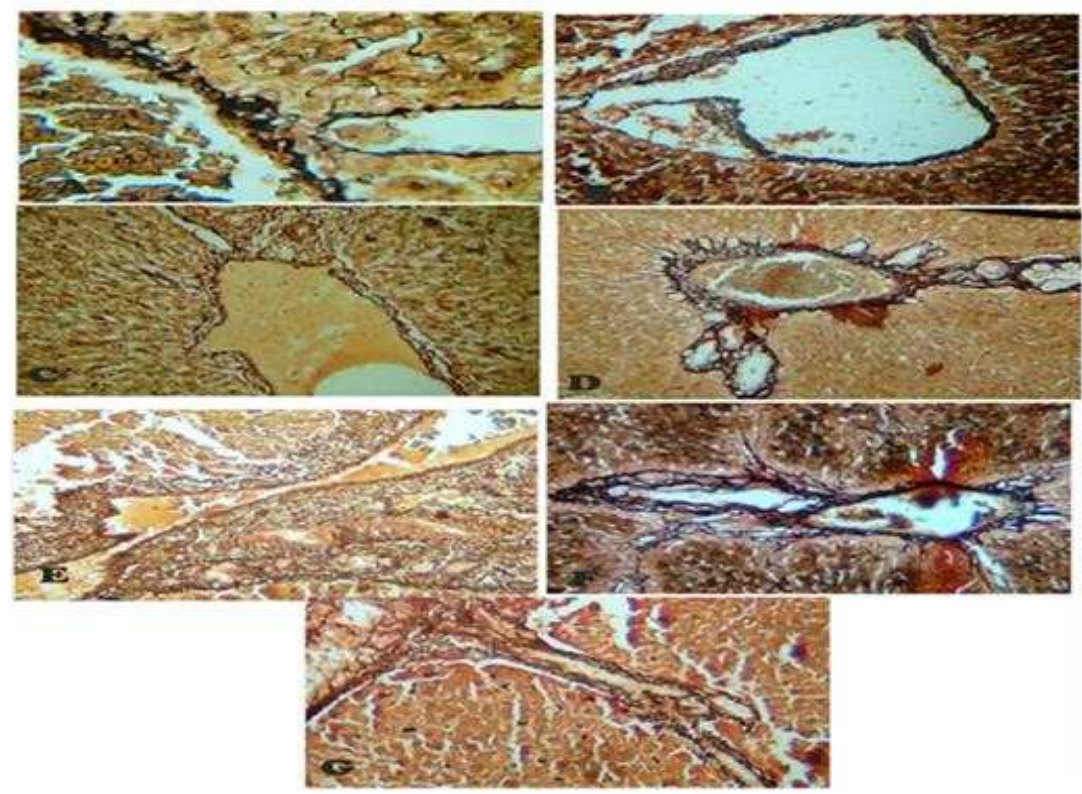

Figure 3: Representative photomicrographs of the liver of control (A) and treated, $(B, C, D, E, F, G)$ groups. Observe normal reticular fibre appearance in all the groups (GS X 400)

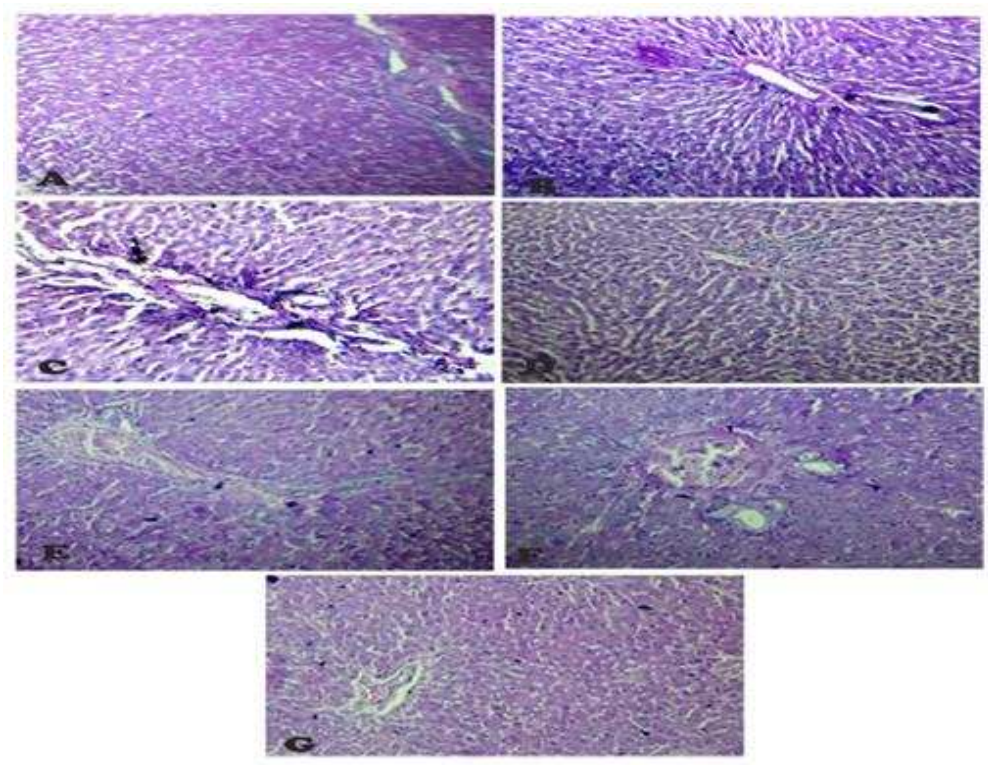

Figure 4: Representative photomicrographs of the liver of control (A) and treated, (B, C, D, E, F, and G) groups. Observe all groups contains PAS (+) glycogen granules (PAS X 100)

presence of prominent collagen fibre as shown in figure $3 \mathrm{~A}, 3 \mathrm{~B}, 3 \mathrm{D}, 3 \mathrm{E}, 3 \mathrm{~F}$ and $3 \mathrm{G}$, except in the negative control group where there was presence of mild fibrosis, this is demonstrated by presence of stroma with young collagen fibre as shown in figure $4 \mathrm{C}$.

\section{Gordon and sweet staining}

Gordon and Sweet staining techniques were used to demonstrate reticular fibre in this study. In the result, the reticular fibre stained black and the nuclei stained black 
or unstained. The reticular fibre in the control group, $B$ (sorghum bicolor), C (PCM), D (PCM+ SB), E (PCM+ SILY), $F(S B+P C M)$, and $G(S I L Y+P C M)$ as shown in figure $4 \mathrm{~A}, 4 \mathrm{~B}, 4 \mathrm{C}, 4 \mathrm{D}, 4 \mathrm{E}, 4 \mathrm{~F}$, and $4 \mathrm{G}$ all appear normal and visible with normal apprearance

\section{Periodic acid schiff's staining}

Periodic Acid Schiff's staining techniques were used to demonstrate glycogen in the liver. PAS stains glycogen magenta in this study. In the result, glycogen stained magenta and the nuclei stained blue. The glycogen in the control group, B (sorghum bicolor only), C (PCM), D $(\mathrm{PCM}+\mathrm{SB}), \mathrm{E}(\mathrm{PCM}+\mathrm{SILY}), \mathrm{F}(\mathrm{SB}+\mathrm{PCM})$, and $\mathrm{G}$ (SILY+PCM) all contains PAS (+) glycogen granules in hepatocytes cytoplasm as shown in figures $5 \mathrm{~A}, 5 \mathrm{~B}, 5 \mathrm{C}$, $5 \mathrm{D}, 5 \mathrm{E}, 5 \mathrm{~F}$ and $5 \mathrm{G}$

\section{CONCLUSION}

The results of this study indicated that $300 \mathrm{mg} / \mathrm{kg} \mathrm{b}$ w of paracetamol was hepatotoxic, and Sorghum bicolor stem bark extract had ameliorative and protective effect on the Paracetamol-induced liver damage.

\section{REFERENCES}

Akande IS, Oseni AA, Biobaku OA (2010). J Cell Anim Biol, 4, 137-142. Baker FJ, Silverton RE (1985). Intro. Med. Lab. Tech. 6th Ed. Butter worth, London
Baranisrinivasan P, Elumalai EK, Sivakumar C, Therasa SV, David E (2009). Hepatoprotective effect of Enicostemma littorale blume and Eclipta alba during ethanol induced oxidative stress in albino rats. Intl. J. Pharm., 5 (4): 268-272.

Duke JA, Wain KK (1981). Medicinal Plants of The World; Computer Index With More Than 85,000 Entries. Three Volumes, Longman UK.

Navarro VJ, Senior JR (2006). Drug-related hepatotoxicity. New England J. Med. 35(4): 731-739.

Nwogu LA, Igwe CU, Emejulu AA (2008). Afr J Biochem Res, 2, 240 242.

Ogwumike OO (2002). Hemopoietic effect of aqueous extract of the leaf sheath of Sorghum bicolor in Albino rats. Afri. J. Biomed. Res. 5:6971

Olayinka ET, Olukowade IL (2010). J Toxicol Environ Health Sci, 2, 8592

Rippka R, Deruelles J, Waterbury JB, Herdeman M, Stainer RY (1979). Generic assignments, strain histories and properties of pure cultures of cyanobacteria. J. Gen Microbiology., 111 (2): 1-6.

- Ita SO, Akpanyung EO, Umoh BI, Ben EE, Ukafia SO (2009). Acetaminophen Induced Hepatic Toxicity: Protective Role of Ageratum conyzoides; Pakistan J. Nutri. 8 (7): 928-932, 2009 ISSN 1680-5194 (C) Asian Network for Scientific Information, 928

Sofowora A (2008). Medicinal Plants and Traditional Medicine in Africa, Spectrum Books Limited, Lagos, Nigeria.

Subramoniam A, Pushpangadan P (1999). Development of phytomedicine for liver diseases. Indian J. Pharmacology, 31 (3): 166-175.

Trumper L, Coux G, Monesterolo LA, Molinas S, Garcia VMC, Elias MM (2004). Effects of acetaminophen on the membrane anchoring of $\mathrm{Na}+\mathrm{K}+\mathrm{ATPase}$ of rat renal cortical cells. Biochemica et Biophysica Acta; 1740: 332-39.

Walker RM, Massey TE, Mc Elligott TF, Racz WJ (1981). Acetaminophen- Induced Hypothermia, Hepatic Congestion, And Modification By $\mathrm{N}$-acetylcysteine In Mice. Toxicol App. Pharmacol.; 59: 500-507. 